This is an electronic reprint of the original article. This reprint may differ from the original in pagination and typographic detail.

Author(s): von Bonsdorff, Pauline

Title: Transformations of the everyday : The social aesthetics of childhood

Year: $\quad 2017$

Version:

Please cite the original version:

von Bonsdorff, P. (2017). Transformations of the everyday : The social aesthetics of childhood. In S. Schinkel, \& I. Herrmann (Eds.), Ästhetiken in Kindheit und Jugend : Sozialisation im Spannungsfeld von Kreativität, Konsum und Distinktion (pp. 319334). Transcript Verlag. Edition Kulturwissenschaft, 100. https://doi.org/10.14361/9783839434833-018

All material supplied via JYX is protected by copyright and other intellectual property rights, and duplication or sale of all or part of any of the repository collections is not permitted, except that material may be duplicated by you for your research use or educational purposes in electronic or print form. You must obtain permission for any other use. Electronic or print copies may not be offered, whether for sale or otherwise to anyone who is not an authorised user. 


\title{
Transformations of the everyday
}

\author{
The social aesthetics of childhood
}

PAULINE VON BONSDORFF

\section{INTRODUCTION}

One of the differences between art and everyday life as generally conceptualized at least in western societies is that art tends to strive towards novelty, uniqueness and individuality, and everyday aesthetics is characterised by familiarity, anonymity, or is even considered to be prosaic. In this paper I want to contribute to everyday aesthetics by tentatively exploring the role of play that noticeably bridges art and everyday aesthetics. Children play, but they are by no means unique in this, and while my examples will mostly relate to children's play I emphasise a more extensive significance of play as a resource in human life. ${ }^{1}$ Like art, playing implies active imagination, and the "mimetic dimension" (cf. Gosetti-Ferencei 2014) is important in various ways. Here I emphasize the performative aspects of play: I focus on what goes on and what is done in the fundamentally social, as I argue, activity of play.

One common denominator of everyday aesthetics and children's play is their social character. ${ }^{2}$ While the aesthetics of childhood can help detect and analyse

1 Among the classical discussions of the cultural and aesthetic significance of play from the 20th century are Johan Huizinga's Homo ludens (1939); Hans-Georg Gadamer's Wahrheit und Methode (1960) and Eugen Fink's Spiel als Weltsymbol (1960). I have discussed some aspects of art and play in Bonsdorff 2005.

2 Social aesthetics is discussed by Arnold Berleant. He describes it as "an aesthetics of the situation" (2005: 30) but does not deal with the performative and interactive aspects. 
aesthetic aspects of social interaction more generally it can also highlight how intersubjectivity is intrinsic to art. $^{3}$ In other words, the aesthetics of childhood can contribute to the analysis and the understanding of both social relationships by making their layered aesthetic character visible; and art, by illuminating the social constitution of aesthetic meaning and value as well as the continuity between seemingly everyday playful behaviour and art.

In this paper I discuss how meaning and value are constituted in shared aesthetic practices and elaborated in imaginative, improvisational play. I indicate the continuity between childhood play and art along two lines. The first is the analogy between what I call "scripted performances" and works of performance art (such as music, theatre, dance, performance art). Both are based on scripts, whether written or memorised, and can be performed repeatedly and by different individuals. They are also remembered and discussed afterwards. The second is the analogy between play-worlds and the fictional worlds of narrative arts. In this case the creator, participants and audience have access to a world that is parallel to everyday reality and can be entered. In this experience, as Jennifer Anna Gosetti-Ferencei writes, "[o]ne does not simply 'pretend' a world, but may be subject to its evocation in an imaginative mode" (ibid.: 437). While having a logic and rules of its own the world may allow the creation of new characters, events and actions; more often it allows at least the transformation and evolution of central characters.

Before presenting the examples in sections 3 and 4 below I describe and motivate my choice of materials and perspective in section 2 . The paper ends (section 5) with elaborations on the more general issues pertaining to the analogy between children's play and art that I have introduced here and that arise through the examples.

\section{THE TEMPORAL PERSPECTIVE}

The examples I use are real-life examples of play between siblings or between grand-parents or parents and children. In a couple of cases I focus on the playworld of a single child. While the examples come from my own family I have not participated in all of them. Some are stories told to me and some were performed for me. In both cases I, as a daughter or mother, was the chosen or relevant audi-

3 The academic interest in intersubjectivity has grown considerably in the last decade, and a similar tendency is visible in art. Its aesthetic theorization is still modest rather than well explored (but note Bourriaud 1998). 
ence rather than a complete stranger: someone who was either part of or concerned with the world, past or present, of the performers. The examples represent three generations of parents and children, historically covering a time-span ranging from the mid-1920s almost to the present day, and reflecting varying contexts of Finnish childhood.

The choice of autobiographical (with one exception) materials is methodologically motivated by my interest in the participants' - especially the children's - perspectives, and the role of play in their life. ${ }^{4}$ I believe that the existential significance of childhood play cannot be analysed very well from a third-person perspective, but presupposes some kind of participatory, insider's point of view. In her book on infants' relationships to other persons Vasudevi Reddy argues for a "second-person approach" to knowing other people (Reddy 2008, especially chapters 2 and 3). Basically this means that there is no unbridgeable gap between individuals in the first place, for who we are is constituted intersubjectively, in relationships where we communicate, act and have access to each other precisely through reciprocal responses and shared meaning-making (see also MerleauPonty 1992: 398-419). A closer look at play confirms this relationality and deepens our understanding of how it takes place.

Then again it is certainly one thing to understand one another in the sense of being able to interact in meaningful and enjoyable ways, and another to be able to articulate this understanding in words; to move from direct interaction to a conceptual or even just narrative interpretation of what playing is about. The participatory perspective must be complemented with hermeneutic reflection building on a contextual understanding and input from relevant life sciences. ${ }^{5}$ Yet our assumptions and expectations about children's abilities in any case affect how we interpret the interaction: what cues we are willing to take and what we make of them. In aiming to understand what children do when they play, and in seeing even young children as intelligent creatures my approach is informed by infant research and childhood studies.

The multidisciplinary research on infant and caregiver interaction that started in the late 1960s provides rich empirical background for my discussion. We know that early interaction is a fine-tuned, synchronised interplay of movement, voice

4 For a thick description of pre-schoolers' play from the perspective of participatory observation, see Corsaro 2003.

5 A contextual understanding is implicit in most analyses of art as well. The difference to children's play is that in play the relevant contextual meaning is typically much more local, having to do with the specific life-world of the child. A recent contextual presentation of art is Marlene Dumas: The Image as Burden (Dumas 2014). 
and gaze between two partners, with rich expressive and even musical qualities. ${ }^{6}$ Early interaction can be construed as a two-way communication where the baby (including neonates) does not mechanically react to or imitate the adult but participates in the dialogue with creative, intentional contributions. In infancy and early childhood social aesthetics is first and foremost an aesthetics of performance which involves (at least) two people and is typically characterized by improvisation and the collaborative creation of small musical narratives. It is an aesthetics in the making, in the present; a temporal aesthetics rather than an object-oriented one. Further, while such interaction can be called a performance it is one where the participants are the primary audience. Infant research shows that young humans' first mode and manner of communication is aesthetic rather than merely instrumental, whether this refers to serving cognitive or practical interests (see Reddy 2008). Another research area that supports the idea of looking for continuities between art and play is childhood studies. This multidisciplinary field has emphasized children's cultural competence and agency as well as the need to study their life-world with a view to their own perspectives, interests and intentions. ${ }^{7}$

The revalorisation of infants' and children's mental capacities and their typical modes of interaction, including play, has produced a rich body of research. The focus is however often on the instrumental benefits of play for the development of learning and cognitive skills (see for example Gopnik 2009). By merging the insights of infant research and childhood studies with the philosophy of art I argue instead for the deep intrinsic, existential, even ontological and political value of play. Play makes a nuanced understanding of the social world possible which is not satisfied merely with what is, but is world-creating and transformative through its overlaps and translations between reality and imagination (on these overlaps, see also Gosetti-Ferencei 2014: 427, 438). Consequently play is relevant for the well-being of communities and societies as well as of individuals.

The fact that the examples are literally familiar to me provides access to many contextual features. Each play situation is particular in time and place, with particular participants, and these factors influence its meaning. The examples also illustrate the continuities in play over generations where the positions of players shift according to changing roles in the family. Play carries references to earlier play, and it also transforms its own traditions. Play can carry forward and enact specific events and traditions, functioning as a kind of local cultural heritage. In this process it becomes an important element of autobiographical shared memories.

6 A rich introduction to this research is provided by Malloch and Trevarthen (2009).

7 A useful introductory source is the Oxford Bibliography on childhood studies: See www.oxfordbibliographies.com/page/childhood-studies. 
Thus, the materials I discuss highlight a temporal perspective on play through transformations and continuities in the play culture of one family and through changing societal contexts and historical time frames. But there is also reason to emphasise the intrinsic temporality of play. By this I refer to the fact that playing often builds on the repetition or continuation of earlier play, whereby both the play itself (how it is performed) and its meaning change. Play and its meaning are temporally layered. To know how to play, to be competent in playing, is to be familiar with the practice, traditions and contexts of play. This temporal structure allows and even invites participation. While the frames constituted by a script or by the rules of the play provide a necessary structure and a space to act in, it is in the temporal dimension where engagement, interaction and creativity take place.

\section{SCRIPTED PERFORMANCES}

The examples of play in this section are what participants typically call "a play". Such plays have a proper context, specific characteristics and typical events or scenes, but they do not need to be fully scripted; mostly they allow improvisation within the given frames. My examples cover by no means the varieties of such plays; rather they highlight certain aspects. In the following I chose to emphasize the existential import of scripted play especially as it addresses the relationship between adults and children.

The first example consists of two plays that two generations of mother and child have played at bed-time. "Bumpy" was a little horse that sometimes carried the girl to bed in the evening if she was too tired to walk, or if she just longed for being carried on her mother's back. This made the unwanted transition to silence, night and sleep easier, but there was also the comfortable feeling of being small again, in intimate contact to her mum. Then again, as the mother was not herself but a horse there was a different kind of companionship as compared to the normal relationship between parent and child. Although the horse was physically bigger and older than the child it was an animal, not an adult, and it carried the girl instead of telling her what to do or where to go.

The mother had a strong mind and after listening to others she made decisions as she saw fit. In the family they sometimes characterised someone, with friendly irony, as being "stubborn as a donkey". When the girl grew into a woman and had a child of her own she turned this idiom into a new version of the play. She came to her child as "the Donkey" and offered to carry him on her back. Like Bumpy, the Donkey worked mostly in evenings and mornings, and carried the child to where he had to go. But in addition, as this mother-child couple had 
a more heated relationship, the Donkey could come forth and lure the child into the zone of animal companionship when words, arguments and other conceivable forms of persuasion did not work.

Unlike parents these animals neither are nor pretend to be authorities. Yet they have their own will and do not necessarily obey the rider. They also seek human care. Being-with-the-animal demands an exercise in generosity, empathy and kindness, but also maturity in order to be fair to the animal whose mind is opaque in more evident, or at least different, ways than the parent's mind. The pleasure of play and make-believe softens disagreements and performs a tacit negotiation where both sides approach each other. The play provides emotional education and opportunities for intimacy and shared rhythms, like in being carried on someone's back and holding on with legs and hands, breathing with the other, or feeling the weight and trust of one's child.

Here is another example of an adult surrendering to the child's world. When the family had visited the uncle and it was time to go home, the father went to the children's room to see how they were doing. His face had an air of anticipation. He was always caught and tied up on the floor in old lace curtains. He protested but could not do anything, only miserably cry for help. When the play was over it was easier for everyone to leave. The play functioned as a ritual of transition and goodbye, but also indicated the reversibility of power. The children prevailed over the adult world, and while the victory was temporary its very existence was promising. This was in the late 1960s.

In the same period the brother and sister used to play drunks: a short play, which made them giggle. They typically stood at the bookshelf, as if in the street, and emptied a miniature bottle each, bottom up. They performed a particular kind of adult life together and for each other. Men like that were around in the streets, they had been in the war it was said. The bottles were also real; their father collected them on flights and gave them to his children to play with. ${ }^{8}$ Being a drunk, playing drunks, was a way of crossing but also attacking the child-adult border: exposing a big person who is not responsible and in power, and who does not behave quite well.

Playing drunks is one form of performing adult life, the varieties of which are legion: playing home, doctor, school, war, police and thieves, etc. My next example of scripted play is on one hand more specific in its reference and ambiguous in its meaning on the other hand. It was created not long after Lars Vilks, the creator of the caricatures of Prophet Muhammad published in the Danish daily

8 Here we should remember the drinking culture of the 1960s and 1970s is different from today's; see, for example, the television drama Mad Men. 
Jyllands-posten, was attacked at a public talk in 2010. Vilks claimed he got a headbutt in his chest. In the play the uncle, shaking his head and talking pensively to himself, utters the words "the prophet Muhammad was a knave". The nephew, who has been standing in the room some 3-5 meters apart then makes a rush, head first, and hits his uncle in the stomach. The uncle totters and we hear a cry of pain and surprise. Both laugh heartily, indeed "sharing funniness" (each time, I assure) ${ }^{9}$

This play is a replay of a real event, and was created as part of a discussion between a seven-year-old boy and his middle-aged uncle. The response to "what happened", which is hard to explain as the answer must rely on contested information, interpretations and evaluations, was answered by re-acting the situation and showing its pattern. As compared to the real event upon which the play was modelled, the uncle's role reminds of the artist's and the nephew's that of the attacker, but more general issues are involved. Simultaneously presented are a number of things to laugh at: head-butts, a child attacking an adult, reacting to words with violent acts, fundamentalism and terrorism, a prophet described as a knave as well as the very energy of a fight that is not for real. There are many borders to cross, and to laugh is to keep all possibilities open (cf. Lewis 2012: 154-173). The play is indeed a training, if not in, then for moral and political judgement. Without any given pedagogical aim it presents some of the difficulties of cultural understanding and the complexities of our reactions.

The performative aspect of the play is crucial. To perform the play is to be, for a moment, the person who reacts violently. It is not to understand or know rationally how that person thinks. To laugh is to laugh at the situation and at a borrowed self.

\section{PARALLEL WORLDS}

The kind of play that I turn to now differs from scripted play in a relative rather than absolute way. Scripted plays are limited in their range of possible events, and the number of actors and type of roles they permit are also limited. But they are not totally unlike parallel worlds, for they stand in a significant relationship to a different order, sphere or world than that of the normal or normative everyday life of the participants. The relationship between the normal or normative and the order of play is addressed, and play negotiates and transforms the every-

9 Cf. Reddy 2008: 183-214. Play of this kind can evolve into identity-creating internal jokes which signal community in other situations to those who are familiar with it. 
day by appropriating elements and producing new perspectives. In this section I introduce examples where the parallel world is the central point of play, whether this world seeps into everyday contexts, as is often the case with imaginary companions, or constitutes a parallel world and society inhabited by an indefinite number of main and more marginal characters.

Aapo was a close friend of the boy but they met mostly at weekends. $\mathrm{He}$ came to their apartment on Friday and went with the family to the country house. The parents had to be reminded of setting a plate for Aapo at the table, but he could serve himself. The mother learned to ask whether Aapo was coming. As he was invisible, the rest of the family did not get to know him very well, but he seemed to be rather quiet and there was no trouble in having him around. Still in the family context the presence of Aapo changed the position of the boy who was the youngest of three siblings In Aapo he had an ally, and by looking after Aapo's needs he could take a more responsible role and ask his parents to adjust to what he was saying rather than the other way around. In the research literature on imagination and imaginary companions there is a discussion of a three-yearold boy with an imaginary pony who was unhappy on arriving at a horse show where he was taken to by his parents, "discover[ing]' ... that the imaginary pony had made other plans and was not there" (cf. Currie/Ravenscroft 2002: 187-188). ${ }^{10}$ But there might be other explanations of his distress than an unwanted development of the fantasy, as has been suggested. Perhaps he had not been told in good time about the plans by his parents. He could not state his discontent by staying at home, as his parents would not allow it, but the pony could. Through the pony he could make a statement although he could not change the course of things.

A parallel world may also exist in a more persistent and as it were wideranging way. ${ }^{11}$ My next example shows such a world, and its presentation needs to include the historical context. The boy who created this world, the Kingdom of Ström in Ingå (a real place), was born in the spring 1918 in Finland, when the country was divided by civil war. In the 1920's the wounds were still open. The boy's father was a doctor who following his professional code of ethics did not take sides in the war, but saw himself as a monarchist. Politics was discussed at home.

From teddy bears, monkeys, tin soldiers and dolls that he got as Birthday and Christmas presents the boy created a state. It was a monarchy ruled by the royal

10 They take the example from Paul L. Harris' The Work of Imagination (2000). For a full-length discussion of imaginary companions, see Taylor 1999.

11 For an overview of psychological research on children's imaginary worlds or "paracosms" see Root-Bernstein 2013. 
family of bears, who did however marry other animals, such that the queen was a hen. The monkeys who were also numerous were mostly social democrats. The fiercest of them, a small guenon, was a trade union leader and communist. The head of police was a lion with a fox detective to his side. The tin soldiers were unstable voters. The parallel world of this kingdom was created, directed and animated by the boy: it was a play basically played by a single child. Its function is thus different from that of the scripted plays described earlier. Rather than an intervention in the order of the everyday, a negotiation or a reflection on a particular event, the Kingdom of Ström and its characters provided a means to study, explore and contemplate the functioning of society. It is scarcely a coincidence that the boy became a professor of social science with special interests in the Finnish party system as well as international relations and peace and conflict research.

A special feature of this world is that it persisted through his life and even beyond. As an adult he presented the citizens of the kingdom to his children. $\mathrm{He}$ opened the chest where the surviving ones shared the space with pairs of pyjamas and old cloth, and introduced them as individuals with names and professions, not as old toys. They were still the persons they had once been, although now retired. ${ }^{12}$ His children knew that these animals would have more to tell: they were definitely surrounded by the aura of their father's childhood, and generally of lived life. ${ }^{13}$ As part of the family history the animals were also companions in the present parent-child relationship and through them the father communicated with his children from the position of the child he once had been. With regret he told them that his mother had donated some animals to charity and had thrown some away when she thought he was too old to still need them.

If imaginary companions are invisible, companions such as the citizens of Ström could be called animated. Both kinds are creatures who simultaneously inhabit everyday reality, the world we think everyone shares, and a fictional world that they bring with them and introduce into the everyday. The strength of imaginary companions is that the child has more autonomy: the child is the sole author with the privilege to act as a translator between the companion and, in most cases, the family.

In addition to single imaginary companions these can also appear as collectives. Here we have a family of four in the 1970s: a father, a mother, and two children. One of them sometimes feels that the others agree against him. This may

12 Except the guenon, the former trade union activist, who in the 1990's became a banker. I foolishly invested a small sum in his bank.

13 Walter Benjamin's discussion of aura as a felt quality of a singular object with a history is definitely applicable here (see Benjamin 2007). 
be because he is more "childish" while the others try to act in a more mature, adult, and serious manner. At such occasions he bows towards the tablecloth or the floor and says "I'll ask what the small ones think". The small ones are an invisible, miniature people that only he can see and communicate with. The rest of the family can hear him talk to them but they do not understand the language. $\mathrm{He}$ cups his hand around his ear to hear their answer. With an expression of triumph he then looks up and says: "The small ones agree with me."

The creator and interpreter of the small ones was the father of the family. In his private life he continued to use play in ways that are similar to children's play: imaginary and animated companions acted as spokesmen, especially with his wife. They could exaggerate, act childishly, tease or provoke, but also function as a third voice that provided a different point of view on the matter at hand. Sometimes they just exposed the diversity of possible reactions in a situation.

\section{REFLECTIONS}

Let me end with some reflections on the similarities and differences between art and play. My starting points are the analogy between scripted play and performance arts on the one hand and on the other hand the analogy between parallel play-worlds and narrative arts. It is however worth to remember that these two kinds of play are not separate categories but rather make visible two of the dimensions where play is similar to art.

First, it is useful to discuss in what sense and in what ways children's play can be seen as an aesthetic mode of thought and action. For a long time "disinterestedness", implying a detached and contemplative, non-interfering stance was seen as essential to aesthetic appreciation. ${ }^{14}$ Play, on the contrary, is mostly participatory and engaged but not so obviously contemplative. Play interferes with and changes things. Rather than aesthetic experience we might therefore use the term "aesthetic agency" when referring to children's play. Aesthetic agency captures better the simultaneously active and passive, creative and appreciative character of play (Bonsdorff, forthcoming). Other characteristics of aesthetic experience such as heightened sensitivity to sensuous and expressive qualities, and imaginative and reflective exploration of situations and objects (including one's own contribution) characterise play as well as art. ${ }^{15}$ In the aesthetic

14 This goes back to Kant (1989).

15 I have elsewhere suggested that these are the elements of aesthetic experience (Bonsdorff 1998: 78-92). 
mode - whether in art or play - we are more present to the world than usually. This is similar to the "lantern consciousness" of childhood that Alison Gopnik contrasts to the "spotlight consciousness" of adult life (Gopnik 2009: 126-132). ${ }^{16}$

Second, in both scripted play and performing arts there are works with particular qualities that carry meaning. Infant research has shown how play begins with action songs and rituals in early infancy: here intersubjectivity is both a motivation and a condition for playful exchanges. Ellen Dissanayake (2000) suggests that the rhythms and modes that are articulated and shared in early childhood are the onto-genetic forerunners of art. Rather than being entities to perceive from outside they are shared spaces to enter, and this is true of their meaning as well: communication is sharing rather than exchange. Action songs and performing arts have in common the importance of timing and rhythm, which are necessary also for successfully performing many of the scripted plays described above. Structural features together with the possibility of repetition give this kind of play the form of a work, similar to that of jokes, anecdotes, and works of performing arts (see Malloch/Trevarthen 2009; also Stern 2010).

Third, like art play is enjoyed for its own sake and provides complex rather than simple pleasure. Both have been described as "autotelic" activities that have their end in themselves. The pleasure they provide includes intellectual, emotional and sensuous aspects as well as awareness of a social context. ${ }^{17}$ Intellectual skills, social know-how and openness are necessary in order to appreciate and perform successfully in both art and play. Humour serves as an interesting example since it involves taste - a key issue in art - as well as timing. Reddy, who prefers to describe infants' merriment in terms of "sharing funniness" suggests that one reason for their interest in humour is its fundamentally social and cultural nature: it is learnt through engagement with other people (Reddy 2008: 183-214). In her book on children's play Helle Skovbjerg Karoff describes play between several children as an exercise and practice of taste, and refers to a "sense" of play in a way that appears close to what we mean by a sense of humour (Karoff 2013: 8295). Taste and the sense of play represent know-how that is value-laden, contextually sensitive and exists as practiced - just like the sense of humour.

Fourth, in play meaning is socially constituted in experimental trials to make sense of the world and make oneself understood. Making sense of things is, as it

16 Describing adult consciousness as the opposite of childhood consciousness is, however, too simple. According to Iain McGilchrist (2009) a more technical vs. holistic approach rather reflects a division of labour between the two brain hemispheres.

17 The issue is not straightforward, and there is a wealth of discussion of how art can be painful or disgusting, yet pleasurable. I cannot go into these questions here. 
were, an existential necessity for children, since much that is self-evident for an adult is not yet known by a child. Here knowledge and imagination are indeed closely connected, which is not to say that young children would be unable to distinguish reality and fantasy (see Reddy 2008: 224 or Gopnik 2009: 30-31). To imagine or pretend is not to think that things really are like that: it is to test and explore how they might be. In play, there is further the joy of immediate response and co-creation. Now artworks are probably less open to new meanings than play; yet compared to many other cultural practices the field of art invites experiments and multiple meanings, complexities and ambiguities, and novel ways of doing things. Furthermore, also the meaning of artworks is socially and contextually constituted; the difference being that their contexts are broader than those of play.

Fifth, both play and art serve remembering and identity-building through processes of reflection, elaboration and re-production. ${ }^{18}$ Structure, meaning and the emotional charge of the experience make it memorable. This provides opportunities for sharing the experience, for reflection and discussion, as well as for new variations. Play can become a significant part of autobiographical memory and one's life-world, where the memory is often a memory of what "we used to play" rather of one particular time. A play can sometimes be performed and transformed over generations,$^{19}$ and a three-year old can insist on a play that she later forgets but that was nevertheless an important part of her life at the time. The very form of play makes it existentially and ontologically significant: identity-forming and world-creating. This is similar to how art is discussed, critiqued and produced: we return to certain works or narrative worlds, compare them and elaborate on them. Some works in particular become central bearers of culture: conserving and/ or transforming its central elements. It is also true however that change is more intimately connected to play than to most forms of art, for play is, as it were, created again in each performance. Even in scripted play the script exists only in the minds of the participants and has no authority other than the one they consent to. While play is most of the time variation and improvisation, art is so more seldom. Yet although art is on the whole more stable, this is a relative difference. ${ }^{20}$

18 For a discussion of elaboration in art on evolutionary lines, see Dissanayake (2000: chapter 5).

19 Corsaro (2003) gives examples of play that is inherited from earlier generations of preschool children.

20 One example from oral narrative culture is the integration of the virgin birth in the Finnish mythological world of "Kalevala". In the last part of the version that Elias Lönnroth (the collector and editor of these epic songs) published in 1849 as the New 
In addition, both historically and in contemporary culture people appropriate materials from fiction, use them in their life and model their life on fictional characters. $^{21}$

Sixth, the imagined world and what is taken to be the real one stand in a reciprocal relationship and inform each other. The world of play and the everyday world touch: the everyday gives the materials for play and play modulates and transforms the everyday. In particular, play has the power to change our perception of the everyday and its manners and modes. Similarity and difference to the everyday are necessary in order for play to be meaningful. A similar relationship prevails between art and reality, however we understand the latter. Art is not necessarily about the everyday, but as Arthur C. Danto pointed out art is always "about" something (Danto 2000) - be it mathematics, the sacred, evil, or the human psyche.

Seventh, both play and art explore, perhaps more than any other themes, relationships and behaviours: ways of being human and living together. Both have social and political import. Above I highlighted the central role of articulations, negotiations and transformations of the child-adult relationship in play. That this relationship is central is no wonder since the order imposed by adults is the main power structure of children's life. This emphasises the importance of genuine, reciprocal and participatory play as a form of communication with and between children. To play with children is to take them seriously. Similarly the greatest part of art produced throughout human history and in different cultures deals with the human condition: with values, knowledge, actions, emotional responses, and so forth.

Eighth, in play as in art awareness of contexts and meta-knowledge (not part of the narrative itself) affects the experience. In play the actual identity and social position of the players make a difference: that the nephew attacks the uncle rather than the other way round. We find similar structures in art: in Cindy Sherman's images of herself as a female movie star the actual social position of the artist/ model is significant. These examples show how play and art give possibilities to test behaviours and attitudes through borrowed selves. In addition to the identity of the performers the audience also makes a difference. Plays are shown to people who are part of the life-world of the players, and this is often true of art as well, especially for the first shows. Another meta-insight of play and art is the recog-

Kalevala, a woman, Marja (the equivalent of Mary) gets pregnant from eating a berry (marja) in the forest and gives birth to a king.

21 This happens in fan cultures generally. Already J.W. v. Goethe's novel Die Leiden des jungen Werthers $(1774,1787)$ gave famously rise to a "Werther fiever". 
nition that humans are playful, imaginative creatures who can communicate with each other in many ways. Thus Bumpy's grandfather wrote and asked when she and her sister would come to visit so they could "throw pillows and do other naughty things" together, and passed on an attractive model of adult-child engagement. ${ }^{22}$

The transformation of the everyday in play is more than a change of modality from real to fictional and back: it is substantial as well. Play is a construction of reality - as much interpretation as transformative imagination, and any simple version of truth is irrelevant in assessing it. The charm and intrinsic value of play is rather related to how much you can do: think, imagine, act.

\section{LITERATUR}

Backman, Fredrik (2013): Min mormor hälsar och säger förlåt [My grandma sends her regards and says I am sorry]. Stockholm: Forum.

Benjamin, Walter (2007): Das Kunstwerk im Zeitalter seiner technischen Reproduzierbarkeit. Frankfurt am Main: Suhrkamp. [Orig. 1939].

Berleant, Arnold (2005): Ideas for a Social Aesthetic. In: Light, Andrew/Smith, Jonathan M. (Hg.): The Aesthetics of Everyday Life. New York: Columbia University Press, S. 23-38

Bonsdorff, Pauline von (1998): The Human Habitat: Aesthetic and Axiological Perspectives. Lahti: International Institute of Applied Aesthetics.

Bonsdorff, Pauline von (2005): Play as Art and Communication: Gadamer and Beyond In: Knuuttila, Seppo/Turunen, Risto/Sevänen, Erkki (Hg.): Aesthetic Culture. Helsinki: Maahenki, S. 257-284.

Bonsdorff, Pauline von (forthcoming): Children's aesthetic agency: the pleasures and power of imagination. In: Delafield-Butt, Jonathan/Dunlop, Aline-Wendy/Trevarthen, Colwyn (Hg.): The Child's Curriculum: Working with the Natural Values of Young Children. Oxford: Oxford University Press.

Bourriaud, Nicolas (1998): Esthétique relationnelle. Dijon: Les Presses du reel.

Corsaro, William A. (2003): “We're Friends, Right?” Inside Kids' Culture. Washington DC: Joseph Henry Press.

Currie, Gregory/Ravenscroft, Ian (2002): Recreative Minds: Imagination in Philosophy and Psychology. Oxford: Clarendon Press.

22 For a recent literary articulation of a similar, although more extreme, grandparent, see Fredrik Backman, Min mormor hälsar och säger förlåt [My grandma sends her regards and says I am sorry] (2013). 
Danto, Arthur C. (2000): Art and Meaning. In: Carroll, Noël (Hg.): Theories of Art Today. Madison: University of Wisconsin Press, S. 130-140.

Dissanayake, Ellen (2000): Art and Intimacy: How the Arts Began. Seattle/London: University of Washington Press.

Donaldson, Margaret (1981): Children's Minds. Glasgow: Fontana/Collins. [Orig. 1978].

Dumas, Marlene (2014): The Image as Burden. (Hg. von Coelewij, Leontine/Sainsbury, Helen/Vischer, Theodora). London: Tate Publishing.

Fink, Eugen (1960): Spiel als Weltsymbol. Stuttgart: Kohlhammer.

Gadamer, Hans-Georg (1960): Wahrheit und Methode. Grundzüge einer philosophischen Hermeneutik. Tübingen: J.C.B. Mohr.

Gopnik, Alison (2009): The Philosophical Baby: What Children's Minds Tell Us About Truth, Love, and the Meaning of Life. New York: Farar, Straus, and Giroux.

Gosetti-Ferencei, Jennifer A. (2014): The Mimetic Dimension: Literature between Neuroscience and Phenomenology. In: British Journal of Aesthetics, Jg. 54, Heft 4, S. $425-$ 448.

Harris, Paul L. (2000): The Work of Imagination. Hoboken: Wiley-Blackwell.

Huizinga, Johan (1939): Homo ludens. Versuch einer Bestimmung des Spielelements der Kultur. Amsterdam: Pantheon. [Orig. 1938].

Kant, Immanuel (1990): Kritik der Urteilskraft. Hamburg: Felix Meiner. [Orig. 1790].

Karoff, Helle S. (2013): Om leg. Legens medier, praktikker og stemninger. København: Akademisk Forlag.

Lewis, Tyson E. (2012): The Aesthetics of Education: Theatre, Curiosity, and Politics in the work of Jacques Rancière and Paulo Freire. New York/London: Continuum Books.

Malloch, Stephen/Trevarthen, Colwyn (Hg.) (2009): Communicative Musicality: Exploring the Basis of Human Companionship. Oxford: Oxford University Press.

McGilchrist, Iain (2009): The Master and his Emissary: The Divided Brain and the Making of the Western World. New Haven/London: Yale University Press.

Merleau-Ponty, Maurice (1992): Phénoménologie de la perception. Paris: Gallimard. [Orig. 1945].

Reddy, Vasudevi (2008): How Infants Know Minds. Cambridge/London: Harvard University Press.

Root-Bernstein, Michelle M. (2013): The Creation of Imaginary Worlds. In: Taylor, Marjorie (Hg.): The Oxford Handbook of the Development of Imagination. Oxford: Oxford University Press, S. 417-437.

Stern, Daniel N. (2010): Forms of Vitality: Exploring Dynamic Experience in Psychology, the Arts, Psychotherapy, and Development. Oxford: Oxford University Press.

Taylor, Marjorie (1999): Imaginary Companions and the Children Who Create Them. New York: Oxford University Press. 